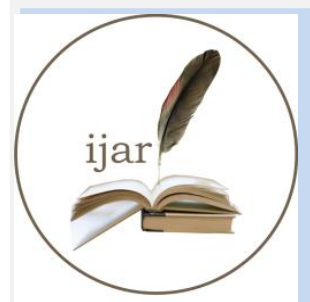

ISSN NO. 2320-5407
Journal Homepage: -www.journalijar.com INTERNATIONAL JOURNAL OF ADVANCED RESEARCH (IJAR)

Article DOI: $10.21474 / \mathrm{IJAR} 01 / 1329$

DOI URL: http://dx.doi.org/10.21474/IJAR01/1329
INTERNATIONAL JOURNAL OF ADVANCED RESEARCH (JJAR)

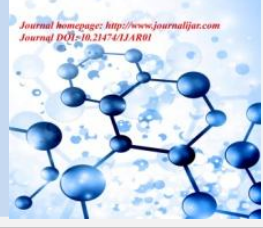

RESEARCH ARTICLE

\title{
SATISFACTION OUTCOMESAFTER SPINAL ANESTHESIA FOR CAESAREAN SECTION IN KAUH IN JEDDAH AND IN MCH IN MAKKAH.
}

\author{
Ahmad A. Saifuddin, Abdullah T. Salem, "Ahmed H. Alhasan,Faisal T. Sugati, Raghad M. Namnqani and \\ Safaa M. Al-Hasani. \\ University Of Jeddah, Batterjee Medical College for Science and Technology, Ibn Sina National College for \\ Medical Studies - Saudi Arabia.
}

\section{Manuscript Info}

Manuscript History

Received: 18 June 2016

Final Accepted: 19 July 2016

Published: August 2016

Key words:-

satisfaction, outcomes, spinal

anesthesia, caesarean section

\section{Abstract}

Aim:To determine the level of the satisfaction in terms of intraoperative pain and postoperative nausea, vomiting, headache, backache among patients receiving spinal anesthesia for caesarean section.Methodology:Cross-sectional survey conducted in maternity and children hospital in Makkah from January 2014 to December 2015. A total of 200 pregnant patients undergoing caesarean section under spinal anesthesia were surveyed. A questionnaire was given to patients to score their satisfaction on a four-point visual analogue scale regarding:1-Pain during surgery, 2-Postoperative Nausea, and Vomiting (PONV), and 3-postoperative headache. The average of responses to questionnaire questions in each of the three areas was taken as the "FundamentalArea Score"(FAS) and the average of these individual (FAS) scores was taken as the Patient Satisfaction score(PSS).Results: There was a high satisfaction score for PONV $(90 \%)$; but satisfaction regarding intra-operative pain/discomfort, postoperative backache and headache has a lower satisfaction score plotted, as (88\%, 87\% and 55\% respectively).Patient's overall level of satisfaction with spinal anesthesia was 90\%.Conclusion: Most of the patients in the study were satisfied with their experience with spinal anesthesia although there was a high frequency of postoperative backache.

Copy Right, IJAR, 2016,. All rights reserved.

\section{Introduction:}

Caesarean section (LSCS) is one of the commonest operations performed in the developing world and is often carried out in difficult circumstances [1]. Spinal anesthesia has many advantages regarding anesthetization for LSCS in which patient still awake and in this situation, the airway(s) is safe [2]. The baby is not sedated and is usually born in a good condition if hypotension-related spinal anesthesia is avoided [3]. If the baby is born with low Apgar score, the anesthesia is free to resuscitate the baby. With a little experience, the technique is as quick as giving a general anesthesia and provide good operating conditions with some reduction in surgical hemorrhage[4]. It has the advantage of giving good pain relief for several hours after surgery and is straightforward to learn and teach. It is inexpensive and appropriate for virtually all cases except those with un-resuscitated preoperative hypovolemia, those with specific contraindications of a bleeding disorder, sepsis at the sight of the injection and allergy to a local 
anesthetic. Spinal anesthesia should be avoided in a patient suspected of having raised intracranial pressure. Patients with hypertensive disease of pregnancy should have their clotting function to be checked [5].

\section{Materials \& Methods:}

Patients who received SA for LSCS during the years 2015-2016 in MCH Hospital, Makkah, and KAUH in Jeddah in KSA, who fulfilled the inclusion criteria for this study were recruited. Exclusion criteria were eclamptic and preeclampsia pregnant patients and those with medical problems e.g. Coagulopathy, heart disease, skin inflection, fetal distress and obstetric complication e.g. cord prolapse and placenta previa.

Data for the study was collected from patients' files by a telephone questionnaire. All spinal anesthesia were conducted by the same anesthesia consultant.

\section{We followed this protocol:-}

We explained the technique and its advantages to the patient. There are widely varying views on spinal anesthesia among different patient populations(also between surgeons). We ensured that the patient understood that pain sensation will be abolished but pulling and pressure sensation will be present during surgery, which may be unpleasant, but is short-lived.All pre-operative preparations are necessary,e.g. antacids, IV access, a wedge, a sucker, an assistant who can give cricoid pressure, full GA, resuscitation drugs, oxygen until the baby is delivered and blood for transfusion. A sterile surface should be prepared for the procedure with all equipment for spinal anesthesiaavailable.

\section{Technique:}

We measured a baseline blood pressure. We pre-loaded the mothers with one liter of normal saline or Ringer's locate solution (Hartmann's) prior to performing the block. We had a vasopressor drawn up and diluted. Ready for injection. The block can be performed either with the mother sitting up with her feet on a stool and her body bent forward with a pillow on her lap; or lying on her side. The spine should well flexed. The injection should be at the level L3/4.

The injection should be performed with full sterile precautions. The skin must be prepared with an alcoholic or iodine based skin preparation. The anesthetist should be wearing sterile, gloves and facemask. A sterile surgical drape should be placed over the patient if they are in the local lateral position. We explained what happened to the patient as this helped them to stay still. We injected local anesthetic to the skin. While awaiting for the local anesthetic to take effect, we drew up the correct dose of the spinal injection, which we plan to use and leave it ready beside the patient on a sterile surface. We made sure that the patient is drawing up the injected dose as needle touches only the inside of the ampoule we are using. The anesthetist should check anesthetic drug name, concentration and expiry date of the spinal anesthetic on two occasions. Almost all serious neurological complications of the spinal blocks had been due to the wrong anesthetic drug being injected into the subarachnoid space due to the lack of vigilance. The anesthetist should also record the batch number and expiry date of the drug on his anesthetic chart.

For the mid-line approach, a spinal needle is introduced ( 23 Gauge) between the lumbar spines to a depth of 2 or 3 $\mathrm{cm}$ until it is firmly held through the interspinous ligament. The spinal needle is inserted with the stillette through the introducer and advanced steadily and carefully feeling for the slight extra resistance of the ligamentum flavum followed by the ease of resistance which occurs when the subarachnoid space is entered. This normally lies at a depth of about 4-6 cm.Depth estimation can be checked from time to time by withdrawing the stillette, seeing if CSF flows back. During entering into the subarachnoid space, the hub of the needle is firmly held in place by resting the back of the left hand(for a right handed person) on the patient's back and holding the hub between thumb and forefinger. The syringe of the spinal anesthetic solution is attached carefully and withdrawn gently on the plunger.CSF should flow back steadily, and can be seen as "oily" streaks if heavy solution is used. If everything is going well, the anesthetic solution is injected steadily and the needle and introducer are withdrawn. A small dressing or a sticking plaster is applied over the puncture wound.The effect of the block can be assessed by testing for loss of temperature sensation using a cotton wool soaked with Ether. An alternative test is done using a sterile needlechecking for loss of pinprick sensation. The block should be above umbilicus and preferably towards the Xiphisternum . The blocks work almost immediately; the anesthetist can allow the surgeon to proceed after 5 minutes.Drugswere 1.2 to $1.4 \mathrm{ml}$ of $5 \%$ lignocaine, and 2.0 to $2.5 \mathrm{mcg}$ of fentanyl. 


\section{Parameters Studied:}

For each patient the following data were identified from his/her file which include: age, weight,gravity and previous spinal anesthetization. Also some fetal outcome data such as Apgar scoring at 1 and 5 minutes, birth weight and sex were included.

Paper questionnaires were given to patients on the post- operative day 2 or 3 , and include the following questions: Was the information adequate?

Did you feel the needle insertion?

Did you feel nausea post operatively?

Did you have vomiting post operatively?

Did you feel pain intraoperatively?

Did you have headache post operatively?

Did you feel backache post operatively?

Were you satisfied with the SA experience?

Would you go through the same experience again?

Would you recommend the epidural for your friends?

Any side-effects noted?

The answers for the questionnaire questions were given by numerical values to be easy analyzed statistically in correlation with other data of the spread sheet. Patients who reported no pain, no nausea, no vomiting, and no headache were considered satisfied. Those who reported one or more of them were considered partially satisfied while those who reported all of them were considered unsatisfied with spinal anesthesia.

\section{Results:}

The study included 200 patients, who received spinal anesthesia within the 1 year study period andresponded to the questionnaire.

As shown in Figure (1), prim gravidas constituted $43.5 \%$ while $56.5 \%$ were multigravidas.

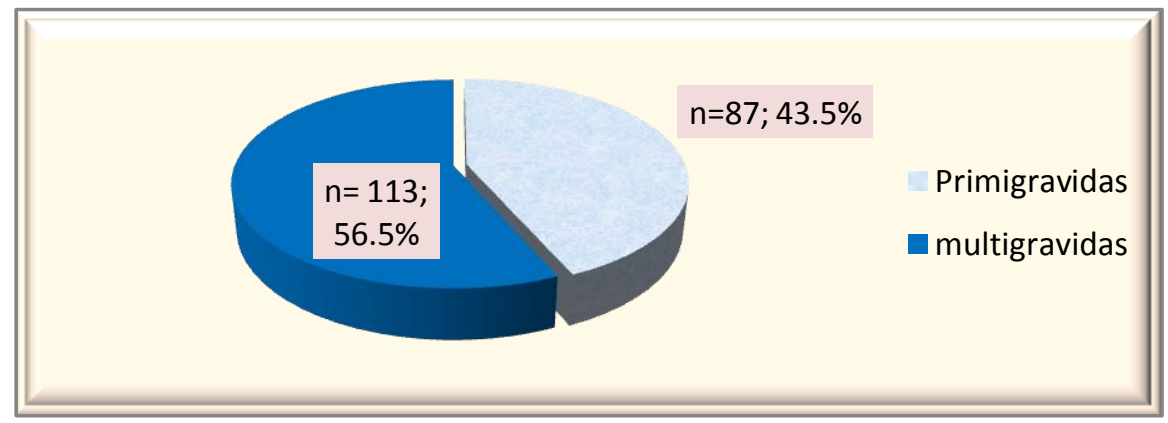

Figure 1:-distribution of the participants according to their gravidity.

As illustrated in table (1), patients' ages ranged from 19 to 44 years with a mean of 27.7years and standard deviation of 5.2years.

Table 1:-Distribution of patients according to their age.

\begin{tabular}{|l|l|l|}
\hline Patients age (years) & Frequency & Percentage \\
\hline$\leq 25$ & 65 & 32.5 \\
$26-35$ & 96 & 48 \\
$>35$ & 39 & 19.5 \\
\hline Range & $19-44$ & \\
Mean \pm SD & $27.7 \pm 5.2$ & \\
\hline
\end{tabular}

Regarding patients` weights, as it is obviously seen from table (2), was ranged from 52 to $96 \mathrm{~kg}(73.6 \pm 10.5)$. The weight of slightly more than one third of patients $(37.5 \%)$ was less than or equal $70 \mathrm{~kg}$ while $31.5 \%$ were between 70 to $80 \mathrm{~kg}$ and $22 \%$ were ranged between 80 and $90 \mathrm{Kg}$. 18 patients (9\%) weighing more than $90 \mathrm{Kg}$. 
Table 2:-Distribution of patients according to their weight.

\begin{tabular}{|l|l|l|}
\hline Patients weight $(\mathrm{kg})$ & Frequency & Percentage \\
\hline$\leq 70$ & 75 & 37.5 \\
$>70-80$ & 63 & 31.5 \\
$>80-90$ & 44 & 22 \\
$>90$ & 18 & 9 \\
\hline Range & $52-96$ & \\
Mean \pm SD & $73.6 \pm 10.5$ & \\
\hline
\end{tabular}

Regarding sources of background experience/information (influence) about spinal anesthesia, relatives and doctors were nearly equally asimportant sources of information whereas media was the least cited source of information(15.5\%). Figure (2)

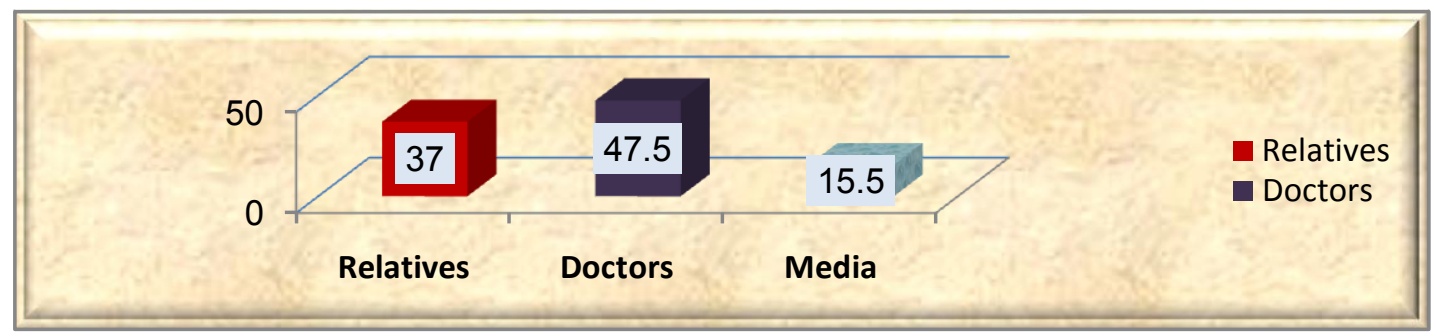

Figure 2:-Source of information about spinal anesthesia

As shown in table (3), 81.1\% of patients whose source of information was doctors were satisfied with spinal anesthesia compared to $75.7 \%$ and $71 \%$ of those whose source of informationwas relatives and media respectively. However, this difference was not statistically significant.

Table 3:-Patients`satisfaction with spinal anesthesia according to their source of information

\begin{tabular}{|l|l|l|}
\hline Source of information & $\begin{array}{l}\text { Satisfied } \\
\text { No. }(\%)\end{array}$ & $\begin{array}{l}\text { Partially/unsatisfied } \\
\text { No. }(\%)\end{array}$ \\
\hline Doctors $(\mathrm{n}=95)$ & $77(81.1)$ & $18(18.9)$ \\
Relatives $(\mathrm{n}=74)$ & $56(75.7)$ & $18(24.3)$ \\
Media $(\mathrm{n}=31)$ & $22(71.0)$ & $8(29.0)$ \\
\hline
\end{tabular}

$\chi^{2}=1.12, \mathrm{DF}=2, \mathrm{p}=0.570$

Regarding the outcome of spinal anesthesia: all neonates had an Apgar score greater than 7 in 1 minute and score of 9 or 10 in 5 minutes.

\section{Development of side effects:}

From table (4), it is evident that more than half of the participants (54\%) had pain with needle insertion, $18 \%$ of patients had nausea, $10 \%$ of them had vomiting, $12 \%$ of them had pain intra-operatively, $13 \%$ of patient had headache while $45 \%$ of the patients had backache. In general, the prevalence of side effects was $55 \%$.

As obvious from table (5), there was no statistically significant relation between the weight of the mother and the incidence of the side effects. Also there was no statistically significant relation between the weight of the baby and the incidence of side effects.

Table 4:-Distribution of spinal anesthesia side effects

\begin{tabular}{|l|l|l|}
\hline Side effects & Frequency & Percentage \\
\hline Pain with needle insertion & 108 & 54 \\
Nausea & 36 & 18 \\
Vomiting & 20 & 10 \\
Intra-operative pain & 24 & 12 \\
Headache & 26 & 13 \\
Backache & 90 & 45 \\
\hline
\end{tabular}


Table 5:-Incidence of side effects according to Patient`s weight

\begin{tabular}{|l|l|l|}
\hline Patients`weight & Frequency & Percentage \\
\hline$\leq 70(75)$ & 39 & 52 \\
$>70-80(63)$ & 33 & 52.4 \\
$>80-90(44)$ & 26 & 59.1 \\
$>90(18)$ & 11 & 61.1 \\
\hline
\end{tabular}

$\chi^{2}=0.94, \mathrm{DF}=3, \mathrm{p}=0.817$

Table 6:- Incidence of side effects according to baby`s weight

\begin{tabular}{|l|l|l|}
\hline Patients`weight & Frequency & Percentage \\
\hline$\leq 3 \mathrm{~kg}(118)$ & 59 & 50 \\
$>3 \mathrm{~kg}(82)$ & 51 & 62.2 \\
\hline
\end{tabular}

$\chi 2=2.91, \mathrm{p}=0.088$

For an overall evaluation, $96 \%$ of all patients would have advised their friends to have SA done as of a method of anesthesia for LSCS (figure 3). In addition, 90.5\% of all patients would repeat the experience in future deliveries (figure 4).

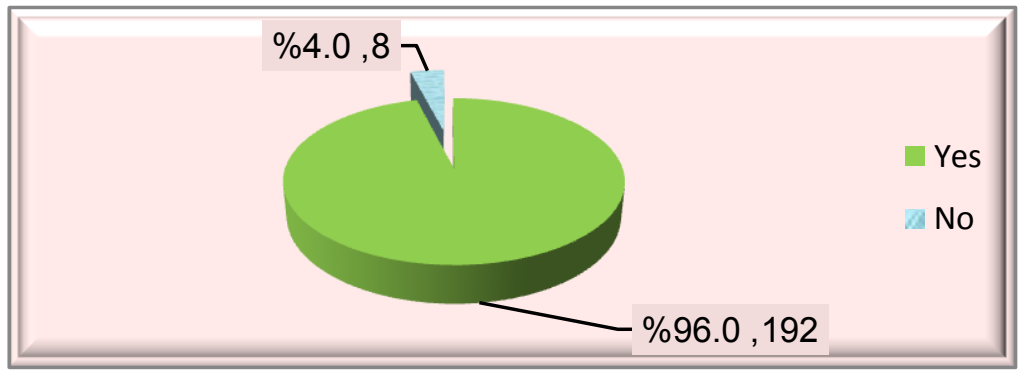

Figure 3:- Patients` advise to their friends to have SA as of a method of anesthesia for LSCS in thefuture.

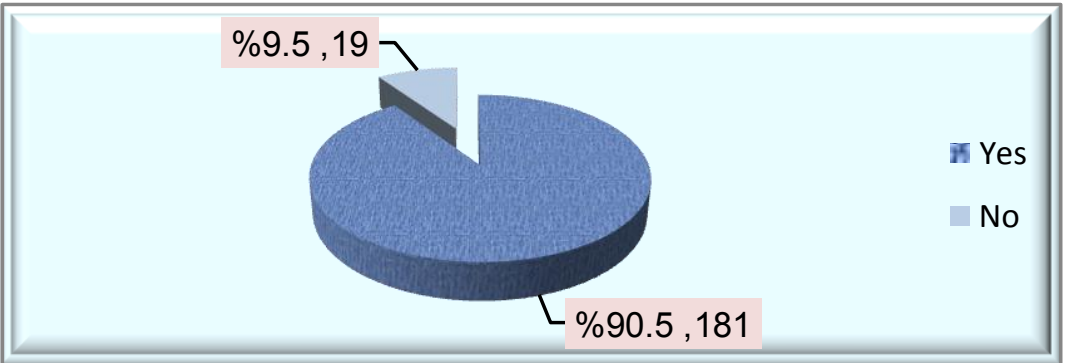

Figure 4:-percentage of patients that would repeat the experience of SA in future deliveries.

\section{Discussion:}

Maternal satisfaction for cesarean section regarding the techniques and outcomes of regional anesthesia and analgesia has been doubtful for years $[6,7]$.

It is still surrounded by old beliefs that decreased its acceptance-even in developed countries-such as the belief that the needle will cause paralysis [8]. Therefore it is not surprising that our study showed the relevance of the source of the information about SA. In our study we found that when doctors were the source of information about SA, the patient satisfaction increased, which could be explained by the clear and scientific evidence of doctors which had a strong positive impact. media was the least source of information that satisfied patients' outcomes.

This could be explained by checking out newspaper articles about spinal and epidural analgesia in the USA, where a significant number of negative articles have been written about one isolated even and many others were involving incorrect information. 
The present data also showed that patient satisfaction with SA depends on many factors in addition to the source of background information/acquaintances experience. It was found that previous experience with SA yields more satisfaction with subsequent SA.

Validity as well as reliability of the questionnaire were verified and showed good results. This study was designed to avoid selection bias and measurement.

Selection bias was eliminated by randomization. Regarding the measurement bias, the tools for measurement for satisfaction were verified and showed good validity and reliability. Data was collected during postoperative period (1-2 hours) in PACU when the patient can recall exactly the events in the operative period (24-28 hours) for these postoperative uncomfortable conditions from SA. The questionnaire in the study was self-administered, which enabled patients to judge freely.

The actual neonatal outcome of the study was excellent and nearly all babies' Apgar scores were> 9 after 5 minutes. Unlike other investigators who stated that in terms of better Apgar score, acid-base status should be maintained and earlier initiation of breast feeding is ensured. SA may be a better choice to a general anesthesia (GA) for CS [9]. This enthusiasm to SA encourage Parsons and Sonnenvel,[10,11] recommend that a pediatrician was not required routinely to attend CS under SA but otherwise should be present for the baby of Sa under GA.

Reports regarding breastfeeding stated that it was started earlier in patients undergone SA than in GA patients for CS.Although both xylaine and marciane were found to be excreted, yet no negative effects were reported in this aspect and researchers came to the conclusion that both drugs used for SA are safe regarding breastfeeding [12].

One of the important issues concerning SA is side-effects. Our study revealed that getting enough background information by the patient about SA did not alter the incidence of side-effects. Youngprimigavidas were more prone to develop side effects than older multigravidas while obese mothers are equally liable to develop side effects as slim mothers [13]. Backache, which could be confused with local tenderness at the puncture site, was the most frequently occurring postepidural complaint (45\%) which could be attributed to the postpartum long bed recumbency despitefrequent advises of early mobilization [14]. Technically, the subarachnoid block was done in the sitting position which might contribute to the postpartum backache [15]. Retrospective studies demonstrated an association between SA and chronic backache of the lower back and leg muscles which lead to prolonged periods of lower posture and decreased perception of muscle strain $[16,17,18,19,20]$. However, this was not the case in our study where motor lock was minimal and the patient could ambulate after 3 hours. Those studies were limited by its recall bias and patient's perception of the association between SA and chronic backache. Several prospective studies(2) have shown that SA for labor did not result in postpartum backache [21,22]. Short term (5-7 days) local tenderness at the site of the needle puncture occurred in about 50\% of mothers [23].

Only $13 \%$ of patients included in the study complained of headache. This side-effect is presumably due to needle in subarachnoid space injected large volume of air which might produce pneumocephalus resulting inseverepost-partum headache which happen characteristically earlier than post-Dural puncture headache [24]. Nausea and vomiting can be unpleasant for patients and has a multi factorial entity such as surgical and anesthetic factors but can be easily treated by antiemetic drugs. Post spinal anesthesia related urinary retention was not mentioned by patients in our study as a side effect, which can be explained by the policy adopted which involve routine urinary catheterization of all patients undergone spinal anesthesia and the fact that urinary catheters being left for 6 hours postpartum [25].

Although approximately $12 \%$ of women would continue to feel pain after spinal anesthesia,which may be confused with pressure sensation during delivery of the baby,it also significantly improve respiratory function [26]. In addition, patients who choose spinal anesthesia have more satisfactionthan women who refused the procedure. Furthermore, it showed no detrimental effect on the neonatal outcome [27].

\section{Conclusion:}

Most of patients were satisfied with their experience of spinal anesthesia although there was a high frequency of postoperative backache. Because advantages of spinal anesthesia are numerous and the fact that unpleasant sideeffects of general anesthesia are avoided, we should encourage all pregnant womenscheduled for elective LSCS to go for spinal anesthesia.

\section{References:-}

1. Sunitha, K., Indira, I., \&Suguna, P. (2015). Clinical study of rupture uterus-assessment of maternal and fetal outcome. IOSR-JDMS, 14(3), 39-45.

2. Liu, S. S., \& McDonald, S. B. (2001). Current issues in spinal anesthesia. The Journal of the American Society of Anesthesiologists, 94(5), 888-906. 
3. Rout, C. C., Rocke, D. A., Levin, J., Gouws, E., \& Reddy, D. (1993). A reevaluation of the role of crystalloid preload in the prevention of hypotension associated with spinal anesthesia for elective cesarean section. Anesthesiology, 79(2), 262-269.

4. Hashim, T. (2015). Spinal Versus General Anaesthesia Fetal \& Maternal Complications (Doctoral dissertation, UOFK).

5. Reynolds, S. F., \& Heffner, J. (2005). Airway management of the critically ill patient: rapid-sequence intubation. CHEST Journal, 127(4), 1397-1412.

6. Sindhvananda, W., Leelanukrom, R., Rodanant, O., \&Sriprajittichai, P. (2004). Maternal satisfaction to epidural and spinal anesthesia for cesarean section. JOURNAL-MEDICAL ASSOCIATION OF THAILAND, 87(6), 628-635.

7. Robinson, P. N., Salmon, P., \&Yentis, S. M. (1998). Maternal satisfaction. International Journal of Obstetric Anesthesia, 7(1), 32-37.

8. BROMAGE, P. R. (1993). Nerve injury and paralysis related to spinal and epidural anesthesia. Regional Anesthesia and Pain Medicine, 18(6), 481-484.

9. Paulson, R.J., Boostanfar, R., Saadat, P., Mor, E., Tourgeman, D.E., Slater, C.C., Francis, M.M. and Jain, J.K. (2003). Obstetric Outcomes in Women of Advanced Reproductive Age. Obstetric Anesthesia Digest, 21.

10. Ng, K., Parsons, J., Cyna, A. M., \& Middleton, P. (2004). Spinal versus epidural anaesthesia for caesarean section. Cochrane Database Syst Rev, 2, CD003765.

11. Morgan, P. J., Halpern, S. H., \& Tarshis, J. (2001). The effects of an increase of central blood volume before spinal anesthesia for cesarean delivery: a qualitative systematic review. Anesthesia \& Analgesia, 92(4), 997-1005.

12. Montgomery, A., \& Hale, T. W. (2006). ABM clinical protocol\# 15: analgesia and anesthesia for the breastfeeding mother. Breastfeeding Medicine, 1(4), 271-277.

13. Salhan, S. (2016). Textbook Of Obstetrics. JP Medical Ltd.

14. Harrington, B. E. (2010). Postdural puncture headache. Advances in Anesthesia, 28(1), 111-146.

15. Chandola, H. C., Mohamed, Z. U., \&Pullani, A. J. (2005). Combined spinal-epidural anaesthesia techniques-a review. Indian J Anaesth, 49(6), 450-458.

16. Hodges, P. W., \& Richardson, C. A. (1998). Delayed postural contraction of transversus abdominis in low back pain associated with movement of the lower limb. Journal of Spinal Disorders \& Techniques, 11(1), 46-56.

17. Friberg, O. R. A. (1983). Clinical symptoms and biomechanics of lumbar spine and hip joint in leg length inequality. Spine, 8(6), 643-651.

18. Nourbakhsh, M. R., \& Arab, A. M. (2002). Relationship between mechanical factors and incidence of low back pain. Journal of Orthopaedic\& Sports Physical Therapy, 32(9), 447-460.

19. Hampl, K. F., Schneider, M. C., Ummenhofer, W., \&Drewe, J. (1995). Transient neurologic symptoms after spinal anesthesia. Anesthesia \& Analgesia, 81(6), 1148-1153.

20. Benzon, H. T., Asher, Y. G., \&Hartrick, C. T. (2016). Back Pain and Neuraxial Anesthesia. Anesthesia \& Analgesia, 122(6), 2047-2058.

21. Chia, Y. Y., Lo, Y., Chen, Y. B., Liu, C. P., Huang, W. C., \& Wen, C. H. (2016). Risk of Chronic Low Back Pain Among Parturients Who Undergo Cesarean Delivery With Neuraxial Anesthesia: A Nationwide Population-Based Retrospective Cohort Study. Medicine, 95(16).

22. O’Neal, M. A., Chang, L. Y., \&Salajegheh, M. K. (2015). Postpartum Spinal Cord, Root, Plexus and Peripheral Nerve Injuries Involving the Lower Extremities: A Practical Approach. Anesthesia \& Analgesia, 120(1), 141-148.

23. Niesen, A. D., \& Jacob, A. K. (2013). Combined spinal-epidural versus epidural analgesia for labor and delivery. Clinics in perinatology, 40(3), 373-384.

24. Ross, A. (1994). Post-dural puncture headache and spinal anesthesia.International anesthesiology clinics, 32(2), 137154.

25. Foon, R., Toozs-Hobson, P., Millns, P., \&Kilby, M. (2010). The impact of anesthesia and mode of delivery on the urinary bladder in the postdelivery period. International Journal of Gynecology \& Obstetrics, 110(2), 114-117.

26. Bromage, P. R. (1961). Continuous lumbar epidural analgesia for obstetrics.Canadian Medical Association Journal, 85(21), 1136.

27. Hodnett, E. D. (2002). Pain and women's satisfaction with the experience of childbirth: a systematic review. American journal of obstetrics and gynecology, 186(5), S160-S172. 